\title{
Living with Inflammatory Bowel Disease: A review of qualitative research studies.
}

\begin{abstract}
:
Background: Inflammatory Bowel Disease is a chronic, untreatable condition represented by two illnesses, Crohn's and Ulcerative Colitis. Despite high incidence in well-developed industrialised countries, and the significant impact of symptoms on patient's quality of life, little is known about living with Inflammatory Bowel Disease.
\end{abstract}

Aim: To explore the patients' experiences of living with Inflammatory Bowel Disease Design: A qualitative systematic review.

Data sources: CINAHL, Medline, British Nursing Index and PsycINFO were searched using the following key words: Inflammatory bowel disease AND experiences. We have limited the search to studies published in English from 2000 to 2017.

Review method: Thematic synthesis.

Results: Data from 23 studies, identified that fatigue, incontinence and uncertainty about future, body image, and lack of information from healthcare professionals dominated the experiences of those living with Inflammatory Bowel Disease. Also, patients living with Inflammatory Bowel Disease were reluctant to disclose their illness due to lack of public awareness and stigma surrounding symptoms. From these, an overarching theme has been identified: Living in isolation and exclusion.

Conclusion: Patients with Inflammatory Bowel Disease face a variety of problems, often their priorities and those of healthcare professionals differ greatly. Healthcare professionals have little evidence needed to provide adequate, holistic care to this group. With a rise in the Inflammatory Bowel Disease population in newly industrialised countries it is estimated that 
the condition is turning into a global disease, potentially making long term care unsustainable. More evidence is needed to understand the concerns of this group.

\section{Contribution of the Paper}

\section{What is already known about the topic?}

- There is little qualitative evidence on patient experiences of living with Inflammatory Bowel Disease.

- Understanding their needs and concerns helps nurses to deliver holistic patient centred care.

\section{What this paper adds}

- People living with Inflammatory Bowel Disease have a wide array of concerns with significant impact on their physiological and emotional wellbeing.

- The impact of the condition on their daily life leads to an existence in isolation and exclusion.

- Further research should be done on adolescents/young adults living with the condition as a significant gap was found in the literature.

Key words: Inflammatory Bowel Disease, patient experience, qualitative review, and nursing.

\section{INTRODUCTION AND BACKGROUND}

Inflammatory Bowel Disease (IBD) is a chronic condition broadly represented by 2 different illnesses, Crohn's Disease (CD) and Ulcerative Colitis (UC). The exact cause is still unknown and IBD remains untreatable for some patients. Patients can experience abdominal pain, diarrhoea, weight loss, chronic fatigue and in some cases extra intestinal manifestations such as joint or eye problems (Day et al, 2012). Symptoms are unpredictable and the condition is characterised by periods when symptoms are quiescent and acute flare ups occur 
(Whayman et al, 2011). Between $25 \%$ and $75 \%$ of IBD patients will experience at some stage episodes of faecal incontinence due to the illness (Norton et al, 2012). Complications as a result of IBD can include bowel strictures resulting in surgery and stoma formation, weakened immune system and increased risk of bowel cancer.

The incidence around the world places Europe as having the highest rates of IBD with UC cases 505:100 000 population, and CD $322: 100$ 000. North America has around 249:100 000 UC patients and 319:100 000 with Crohn's, whilst Asia and Middle East reported around 5:100000 Crohn's and 6:100000 UC patients (Molodecky et al, 2012). There is no data regarding racial distribution, however there are reports of increased incidence in Asian and African countries, but one can argue that this may be due to improved diagnosis. Disparity in access to healthcare in low income countries may also contribute to the low numbers reported. Given the chronic nature of the symptoms and the severity of these, the condition has a significant impact on the patients' life, not to mention costs to the health services. As an example the lifelong costs for the care of an IBD patient are comparable to the costs for some cancer patients (Mowatt et al, 2011).

There are a wealth of quantitative studies which measure quality of life, the concerns and worries of those living with IBD, or the impact of symptoms on daily living, with the majority suggesting a negative impact of the condition on the health related quality of life. However, these studies do not give an insight on the patient experience. Studies drawing on qualitative data can provide rich detail about the lived experience of patients with IBD, attributing broader meanings and enhancing understanding.

\section{AIM}

In this literature review we sought to identify and synthesise the existing evidence which 
provided a qualitative in-depth account of the experiences of those living with IBD, in order to understand their concerns and impact of the illness on daily life.

Research question: What are the experiences of those living with IBD?

\section{DESIGN}

Thomas and Harden's (2008) thematic synthesis approach was used for this review and ENTREQ guidelines were followed for reporting systematic qualitative reviews (Tong et al, 2012).

\section{Search methods}

A systematic literature search was run on several electronic databases: CINAHL, British Nursing Index Database, Medline and PsycINFO. The following search terms were used: IBD OR inflammatory bowel disease OR Crohn's disease OR ulcerative colitis AND Experiences OR perceptions OR attitudes OR views. Searches were limited to 'English language' and 'human' from 2000 to 2017 (December). A further hand search was performed through the reference lists of the articles identified as answering the research question, with one thesis being identified and retained for review. We read all the abstracts in first instance as a study screening method.

Table 1.

\begin{tabular}{|l|l|}
\hline Inclusion criteria & Exclusion criteria \\
\hline Primary research & $\begin{array}{l}\text { Research looking solely at experiences } \\
\text { following surgery in IBD (i.e. stoma) }\end{array}$ \\
\hline No age restrictions & $\begin{array}{l}\text { Experiences related to treatment and the } \\
\text { provision of care. }\end{array}$ \\
\hline IBD diagnostic & $\begin{array}{l}\text { Studies where IBD and other chronic illness } \\
\text { were analysed together }\end{array}$ \\
\hline Experience of living with IBD & Quantitative research \\
\hline English language & \\
\hline Published 2000-2017 & \\
\hline
\end{tabular}




\section{Search outcome}

A total of 705 studies were retrieved, and after removing the duplicates 663 papers were retained. From these, all the quantitative studies were discarded, leaving 36 full texts that were read after the abstracts were matched to the inclusion/exclusion criteria and were confirmed as primary research of a qualitative nature. Studies where IBD was not the main focus were removed due to the difficulties in correctly assessing what statements belonged to our group of interest if other long term conditions were compared to IBD. Similarly, those which did not represent patients' perspectives were excluded. As a result, 23 studies were included in the review, of which 5 were theses and dissertations (see figure 1).

\section{Figure 1: Prisma diagram}

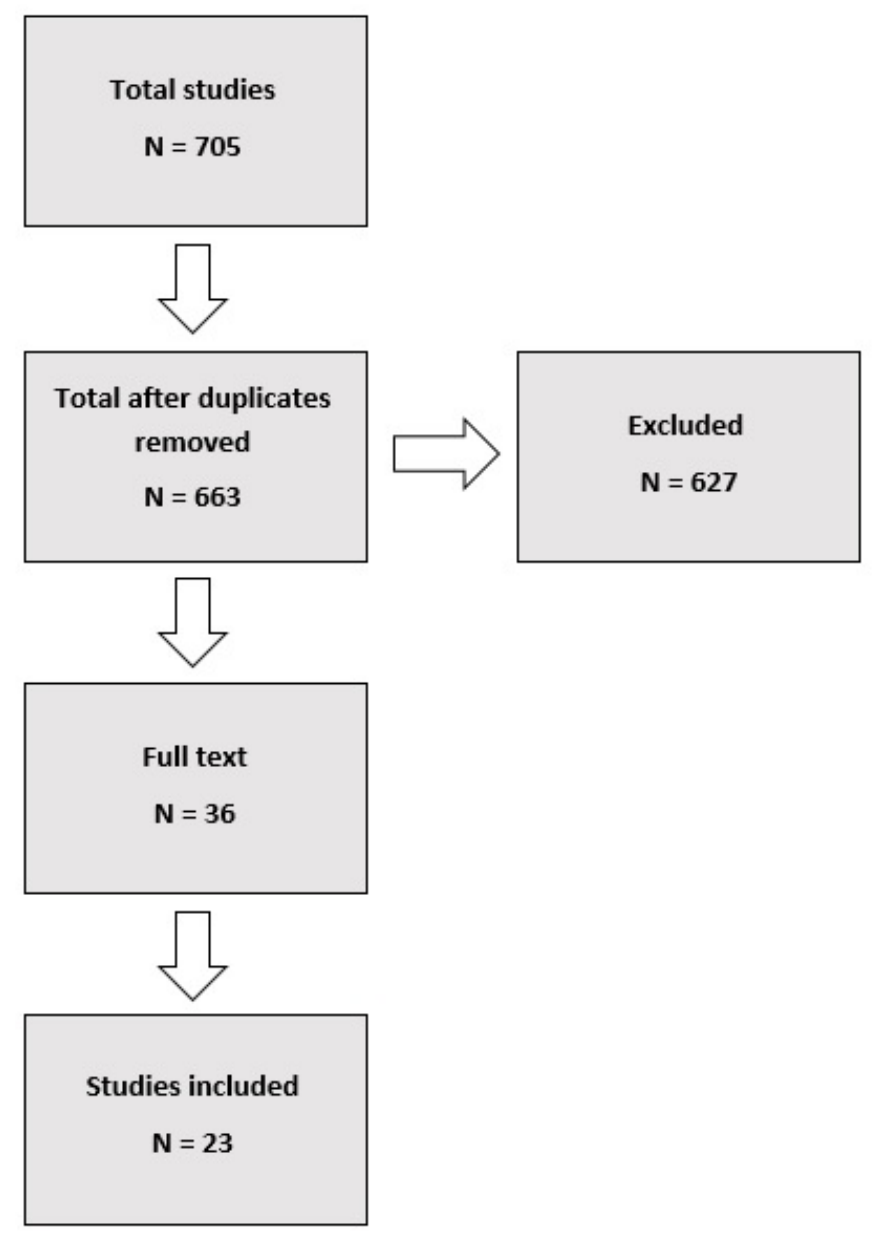




\section{Quality appraisal}

All the studies included were subject to critical appraisal guided by the Critical Appraisal Skills Practice tool (2017) for appraising qualitative research. All authors were involved in the appraisal and the decision as to which studies met the inclusion/exclusion criteria. It was concluded that all used appropriate methods for their aims, and it was noted that newer studies had a more detailed methodology than older publications. Although several papers lacked detail regarding ethical issues, the decision to include them was taken based on the fact that reporting and publishing standards have changed significantly in the past 17 years, therefore at the time of their publishing these papers have met the criteria existing at that time. Some difficulty was encountered in evaluating the auto ethnographic research, but the decision to include them in the review was taken as they provide valuable insight to the lived experience of this group, evoking a believable and possible experience (Ellis and Buchner, 2000). The autoethnographic studies included in this review were appraised following Richardson's (2000) criteria for autoethnography reviews. Autoethnography should be appraised based on credibility, accountability and dependability (Medford, 2006) and ultimately on the judgement of an experienced researcher (Le Roux, 2016).

\section{Data abstraction}

Thomas and Harden's (2008) framework was used for analysis as data originated from a range of studies that were relevant to the research question. The concerns and perspectives described by those living with the condition were identified in the studies, annotated and assigned to a code (Aveyard, 2016). Concerns of IBD population identified in previous literature (Casati et al, 2000; Stjernman et al, 2010) were used at first for coding using framework analysis. Following line-by-line coding of all data in the studies included, more codes were identified and used to define the descriptive subthemes. 


\section{Synthesis}

From the descriptive subthemes, analytical themes were generated through inductive analysis; providing new interpretations to the data from the primary studies. After preliminary themes were identified by the first author, all three authors audited the process, refined the themes and a consensus was made to final naming of themes. Once the analytical themes were named, a second assessment of each studies' contribution to these themes was conducted (Dixon-Woods, 2006).

\section{RESULTS}

Data was collected from 18 studies, 4 theses and 1 dissertation that met the inclusion/exclusion criteria. Of these, 19 used qualitative methods and 4 mixed methods; however, only the qualitative data from these was used for our review. The total sample was 825; geographical areas of the studies was mainly UK and Europe, followed by Canada, USA Australia and New Zealand (see figure 2).

Figure 2 


\section{GEOGRAPHICAL AREA OF STUDIES}

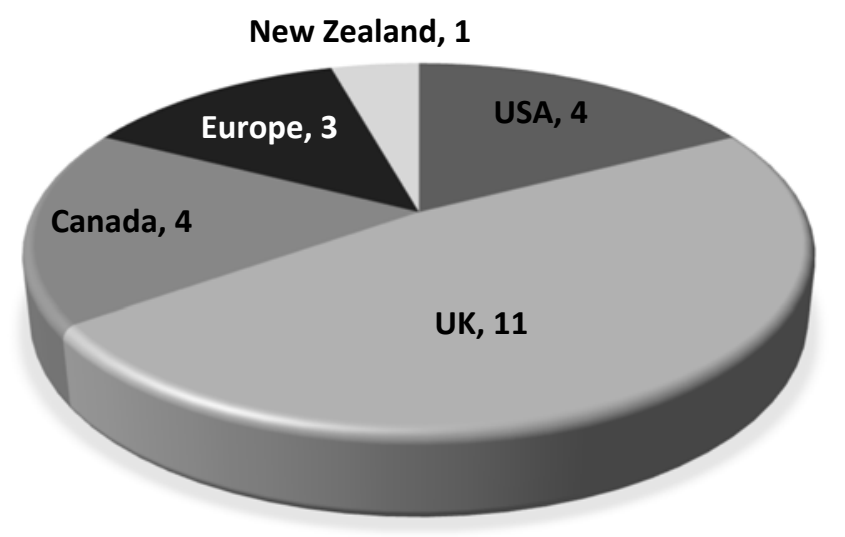

Little information was provided in terms of ethnic diversity, some studies giving limited details regarding the sample they have included, but most of the studies' limitations suggested that a predominantly white Caucasian population was included. In terms of the age groups studied, the majority of the population included in the selected studies were adults, and from the limited information given regarding the ethnicity, it appears that around $6 \%$ were black or ethnic minorities.

Analysis of the studies demonstrated the profound impact on the everyday life of those living with IBD. The main finding was the overarching theme Living in isolation and exclusion, as all the identified subordinate themes lead to isolation and exclusion. The following subordinate themes were identified: living in isolation and exclusion, living in secrecy, living with a flawed body, living with restriction and living in fear. Each theme is comprised of a number of subthemes (see figure 3). 
Figure 3. Themes and subthemes

\section{LIVING IN ISOLATION AND EXCLUSION}

\begin{tabular}{|c|c|}
\hline $\begin{array}{l}\text { Living with } \\
\text { exhaustion }\end{array}$ & - feeling tired \\
\hline $\begin{array}{l}\text { Living in a flawed } \\
\text { body }\end{array}$ & $\begin{array}{l}\text { - losing control } \\
\text { - damaged body image }\end{array}$ \\
\hline Living in secrecy & $\begin{array}{l}\text { - invisible ilness } \\
\text { •not being believed } \\
\text { •lack of public awareness }\end{array}$ \\
\hline $\begin{array}{l}\text { Living with } \\
\text { restriction }\end{array}$ & $\begin{array}{l}\text { - living witrh unpredictability } \\
\text { - feeling a burden } \\
\text { - diet constraints } \\
\text { - feeling unable to reach full potential }\end{array}$ \\
\hline Living in fear & $\begin{array}{l}\text { - fear of unknown } \\
\text { - fear of complications }\end{array}$ \\
\hline
\end{tabular}

The themes were found in almost every study with few exceptions in cases where the study was looking at specific aspects of IBD impact, such as fatigue or diet (see table 2).

Table 2. Strength of themes

\begin{tabular}{|l|l|l|l|l|l|}
\hline Author & $\begin{array}{l}\text { Living in } \\
\text { secrecy }\end{array}$ & $\begin{array}{l}\text { Living in a } \\
\text { flawed } \\
\text { body }\end{array}$ & $\begin{array}{l}\text { Living with } \\
\text { exhaustion }\end{array}$ & $\begin{array}{l}\text { Living with } \\
\text { restriction }\end{array}$ & $\begin{array}{l}\text { Living } \\
\text { with fear }\end{array}$ \\
\hline Alexakis et al & $\checkmark$ & $\checkmark$ & $\checkmark$ & $\checkmark$ & $\checkmark$ \\
\hline Burger, J & $\checkmark$ & $\checkmark$ & $\checkmark$ & & \\
\hline Barned, C. et al. & $\checkmark$ & $\checkmark$ & $\checkmark$ & $\checkmark$ & \\
\hline Compton, I & $\checkmark$ & & $\checkmark$ & $\checkmark$ & $\checkmark$ \\
\hline Cooper et al & $\checkmark$ & $\checkmark$ & $\checkmark$ & $\checkmark$ & \\
\hline $\begin{array}{l}\text { Czuber-Dochan } \\
\text { et al }\end{array}$ & $\checkmark$ & $\checkmark$ & $\checkmark$ & $\checkmark$ & $\checkmark$ \\
\hline Daniel,J & $\checkmark$ & $\checkmark$ & $\checkmark$ & $\checkmark$ & $\checkmark$ \\
\hline Defenbaugh,N & $\checkmark$ & $\checkmark$ & $\checkmark$ & $\checkmark$ & \\
\hline Devlen et al & $\checkmark$ & & $\checkmark$ & & \\
\hline Dibley et al & $\checkmark$ & $\checkmark$ & $\checkmark$ & $\checkmark$ & \\
\hline Dibley L & $\checkmark$ & $\checkmark$ & $\checkmark$ & $\checkmark$ & \\
\hline Hall et al & $\checkmark$ & $\checkmark$ & $\checkmark$ & $\checkmark$ & \\
\hline Lindfred et al & & $\checkmark$ & $\checkmark$ & $\checkmark$ & \\
\hline
\end{tabular}




\begin{tabular}{|l|l|l|l|l|l|}
\hline Lynch \&Spence & & $\checkmark$ & $\checkmark$ & & $\checkmark$ \\
\hline Matini \& Ogden & $\checkmark$ & & $\checkmark$ & & $\checkmark$ \\
\hline Moore, I & $\checkmark$ & $\checkmark$ & $\checkmark$ & $\checkmark$ & \\
\hline Mukherjee et al & $\checkmark$ & $\checkmark$ & $\checkmark$ & $\checkmark$ & \\
\hline $\begin{array}{l}\text { Micallef- } \\
\text { Konewo,E }\end{array}$ & $\checkmark$ & $\checkmark$ & $\checkmark$ & $\checkmark$ & \\
\hline Nicholas D et al & $\checkmark$ & & & & \\
\hline Palant et al & $\checkmark$ & $\checkmark$ & $\checkmark$ & $\checkmark$ & \\
\hline Prince et al & & $\checkmark$ & $\checkmark$ & $\checkmark$ & \\
\hline Sammut et al & $\checkmark$ & $\checkmark$ & $\checkmark$ & $\checkmark$ & $\checkmark$ \\
\hline Sykes et al & $\checkmark$ & $\checkmark$ & $\checkmark$ & $\checkmark$ & \\
\hline
\end{tabular}

\section{Living with exhaustion}

Fatigue has been given much attention over the years as being one of the most distressing consequences of the disease reported by patients. The lack of energy was expressed by participants in most of the studies from 2000 onwards (Cooper et al, 2010; Sykes et al, 2015; Sammut et al, 2015;; Dibley et al, 2014). There are various aspects of fatigue that were investigated such as causes, management, impact on daily life and support seeking (CzuberDochan et al, 2012). However, the most inconvenient, from patients' perspective was the effect that fatigue had on the participants' life. The constant struggle to perform normal daily activities was highlighted in a few studies (Cooper et al, 2010; Czuber-Dochan et al, 2012; Burger, 2005; Moore, 2012; Sykes et al, 2015)

'It's not just the tiredness, it's this feeling of not being able to bother with anything... just losing interest (Czuber-Dochan et al, 2012, pg. 1991).

This is also illustrated by a statement showing the effect of fatigue depicted in an auto ethnographic study (Moore, 2012, pg.203):

'...I can feel the effort to keep my eyes open, their heaviness drags my whole posture lower and lower in my chair. 'ARRRGGGHHHHH'I just let out. 'I hate feeling tired'. 
In some instances study participants had even adapted their family planning according to their energy levels dictated by the condition and decided to only have one child (CzuberDochan et al, 2012). Others felt that they could not look after more children '...I decided not to take the risk and bring another child into the world. I probably would not even be able to look after him.'(Sammut et al, 2015, pg.2663)

The participants in the studies above were all adults. Studies looking at children and adolescents indicate fatigue is a problem but this is expressed as reduced levels of physical activity. Younger patients who led an active life prior to their diagnosis were most affected by the limitations associated with the lack of energy (Moore, 2012). Some patients denied that they had reduced the level of physical activity due to illness, although during relapses all were unable to engage in exercise as a result of low energy levels (Sykes et al, 2015).

\section{Living in secrecy}

Participants described living in secrecy, associated with not disclosing their condition. This theme comprised several facets, including having an invisible illness and not being believed, to lack of public awareness. These are discussed in detail below.

\section{Having an Invisible illness}

Secrecy surrounding the condition was described by participants in most of the studies. Adults and younger patients talked equally about hiding their illness because they did not want to discuss embarrassing symptoms 'Well it's just something I have to live with. Bowel disease, the subject's not right for conversation.'(Hall et al, 2005, pg.451). MicaleffKowenko (201) also identified secrecy around embarrassing symptoms as a barrier to disclosure in her study with children living with IBD. 
Another reason for their secrecy resided in the difficulties of dealing with an invisible illness. There are no obvious signs of disability as the physical appearance of an IBD patient is suggestive of a healthy person.

'It's only when you tell people that you've got Crohn's disease and the fact that nobody had a clue, oh what's that then, you know what I mean, that's the sort of response you get, and nobody actually thinks there' anything wrong with you, and it's one of those invisible illnesses that you look OK on the outside but on the inside is a totally different story.' (Matini and Ogden, 2015, p.2497).

In several circumstances this invisibility caused those living with the condition to avoid giving explanations that would be embarrassing or would question their credibility.

Defenbaugh (2007) made a metaphoric comparison between her physical appearance and her bowel; both of which looked healthy to the naked eye - the reality being different when put under the microscope. Having an invisible illness is exacerbated by a lack of public awareness surrounding the condition.

\section{Lack of public awareness}

Lack of public awareness was described by participants in several studies. However, one study indicated that this might be more evident in certain cultures.

Alexakis et al (2015) found that participants from different cultures felt that their communities had little or no awareness of IBD. Patients from ethnic minorities avoided disclosing the condition even to close family members. 


\section{Not being believed}

Having an invisible illness had also raised questions for some of the participants' friends and family, which made them feel that they were not believed. Some felt that even amongst healthcare providers there were some who did not believe them:

'Once I was admitted to casualty with acute pain and still he (the doctor) told me that nothing was wrong...In the meantime I took tranquilizers and he (the doctor) told me to continue taking them since I was having panic attacks....but I knew that something was wrong...I began to doubt whether my family believed me or not and I would fill up with anger' (Sammut et al, 2015, p.2663)

Children and adolescents similarly reported not being taken seriously (Alexakis et al, 2014; Daniel, 2005) or not being believed, which ultimately resulted in them not disclosing their condition. Not being believed was in constant evidence in both adult and young population who participated in the studies.

\section{Living in a flawed body}

The research literature revealed many participants experienced a sense of living in a flawed body; evidenced through a sense of loss of control over it, and the sense of having a damaged body image. These are discussed in detail below.

\section{Losing control over your body}

Frequently participants described how the inability to have control over aspects of their body gave them the perception of living in a flawed body. The fear of loss of bowel control was reported by most studies. To address this, participants described finding ways to gain some control over the situation and avoid such accidents (Dibley, 2014) (Hall et al, 2005), but most of them chose to avoid going out. 
Concerns related to body control or continence were evident in adult studies, whereas in young populations this subtheme was more subtle, often being referred to as an inconvenience caused by symptoms of bowel urgency.

\section{Damaged body image}

Concerns regarding body image were attributed to various reasons. The side effects of the medication: 'they call me a marshmallow, and pull on my cheeks when I'm on prednisone. This bugs me.'(Nicholas et al, 2007) or the surgery resulting in stoma formation also contributed to an altered body image.

Defenbaugh (2007) talked about the 'grotesque body' in her auto ethnography study which portrayed a suggestive image about her 'messy, leaky body' (Defenbaugh 2007, pg.55). Similar views were identified in Daniel (2002) who quoted a participant who felt 'damaged in some way'. Dibley et al (2014) stated that life changing decisions grounded on body image issues resulted in the choice for celibacy following stoma formation in the case of a participant. No further details were given; however, it suggested the body image had a considerable role in the decision. Other excerpts from the same study showed a similar pattern:

'From the day I was told (the stoma) is basically going to be reversed, I decided that I wasn't even going to have any interest in relationships for the period I had the stoma.' (Dibley et al, 2014, p.26)

Body image was found to be of importance mainly in younger patients in contrast to the older adults. In studies with children we identified that the peer acceptance was affected based on looking or being different. Some felt excluded by not being 'normal' and this also led to isolation: 'I feel isolated and ridiculed' (Nicholas et al, 2007, p.7). 


\section{Living with restriction}

Unpredictability of the symptoms, dietary changes, feeling unable to reach full potential and feeling a burden to loved ones, together comprised the sense of a life of restriction.

\section{Living with unpredictability}

Most of those interviewed have commented on the unpredictability of the symptoms:

'There's really nothing to do to prevent that because that's my biggest thing, like what can I do to prevent things when I 'm just doing what I do every day and I'm not changing anything and it's still happening to me out of the blue. You know I just don't know how to deal with that...' (Compton, 2002, p.40)

On many occasions people felt they were in a permanent state of unrest, with little or no control over maintaining some stability. In an attempt to gain some control over the unpredictability of the disease, the majority decided to reduce to a minimum any social events and activities that would be hard to manage should the symptoms return.

‘... r remember the last time I went out... I was in a bar and I had an attack of pain and I needed to use the toilet, I rushed to the toilet, something which I really hate to do when I am out... By the time I was dressing up to go out I felt the need to sit on the toilet again and then I promised myself never to go out again' (Sammut et al, 2015, p.2664)

Dealing with the unpredictability had limited the participants' ability to plan for the future and in many instances this was closely related to them not reaching full potential.

\section{Feeling unable to reach full potential}

Difficulties with reaching full potential has been commonly found in younger adults. Absenteeism from school as a result of the condition was found to affect their career prospects, 
some choose a career path that would fit their condition as opposed to what they would have liked to do (Nicholas et al, 2007).

'...for like the last 2 years literally, I was literally at home unless you had to go to the hospital and I became isolated, so education wise, I kind of , I don't see myself doing it anymore. I've lost that. (Female, aged 20, CD) (Alexakis et al, 2015, p.670)

Adults touched on this aspect reporting adjusting their employment to their condition by taking part time employment or, in some cases, unemployment altogether.

\section{Dietary constraints}

Restriction imposed by condition was also connected to the diet. Having to change the way they eat after diagnosis has been identified in studies looking specifically at this (Palant et al, 2013; Price et al, 2011), although in several others it was identified as a measure taken to prevent flare ups. Food has significant cultural connotations and some of those affected by the condition described the added struggle in maintaining the social norms expected by their cultural/ethnic group. This aspect was particularly emphasised in a study looking into challenges faced by black ethnic minorities living with IBD (Alexakis et al, 2015).

'It's just the way the ethnic community is and with food and obviously food is a big part of the culture....everything is based around food, weddings are based around food, you go into people's houses, it's all about bringing as much food as you can and that's what entertaining is. That's the thing isn 't it?' (Alexakis et al, 2015, p.668).

Similarly, some patients reported that the condition interfered with their religious eating practices; the same study suggest that more than half of those interviewed could not fast during Ramadan as a consequence of their condition. 
Nevertheless food restrictions or diet alteration was not only specific to minority cultures. People from dominant cultures also reported how living with IBD had changed their eating habits. Some of these were due to the potential of exacerbating their symptoms, others due to the food regimens required at times of bowel rest (Palant et al, 2013) (Moore, 2012). Not all the patients were forced to change their eating habits, although one study stated that $82 \%$ of the IBD patients invited to take part had reported issues related to food (Price et al, 2011). Statements of those who didn't view food as a concern were also found in Cooper et al (2010). In children and adolescents the issues surrounding food were related to the food restrictions required at times for bowel rest (Nicholas et al, 2007).

\section{Feeling a burden}

Some have given accounts on how IBD affected them and their family and made them feel a burden by requiring a lot of support (Sykes et al, 2015) (Hall et al, 2005). Feeling guilty or feeling a burden was found to be quite similar concepts in the studies included:

'I think there's got to be at least five times I can think of that I basically tried to push him( boyfriend) out of my life...It's somehow easier to do that than to deal with the guilt of not being able to...you know...be a normal girlfriend for him' (Daniel, 2002, p.88)

Feelings of guilt were common in parents with IBD who felt unable to provide the care they wanted for their children. Restrictions were made on where they could take the children or what activities they could do together (Mukherjee et al, 2002).

\section{Living in fear}

Fear took many aspects but more prevalent was found to be the fear of complications and fear of the unknown due to the lack of information from healthcare professionals. 


\section{Fear of complications}

This was identified in various patient statements. Whether this was the fear of living with the condition, fear of having surgery, the fear of developing cancer or passing the disease to the next generation. It posed a heavy weight on people with IBD. Younger patients have even expressed the fear of dying:

'It was not so much fear of having the condition but fear of dying.... You think you can avoid dying but you're just going through hell. I was basically skin and bones....' (Lynch and Spence, 2007, p.226)

Deffenbaugh (2007) talks about her fear of surgery: 'I ask on behalf of my body who is scared shitless as she stares into your wounds and ponders a surgical fate. I ask because I am afraid.' (p.137).

\section{Fear of the unknown}

This, in many cases, resulted from lack of information from the healthcare professionals involved in the care of the participants. It appeared that the less information about the progress and complications of IBD was given, the more reported to be fearful. Also, experiences of clinical care where non specialists had limited knowledge of IBD had exacerbated the fear of the unknown coupled with loss of trust in healthcare professionals (Alexakis et al,2015).

Similar findings were reported by Cooper et al (2010) who stated that non specialist IBD healthcare professionals involved in the care of the participants was identified to cause significant concerns to the participants, by attributing symptoms to other conditions.

\section{DISCUSSION}


This review has captured the accounts of patients' experiences and highlights the complex challenges of living with IBD. The theme that was identified in all of the studies, irrespective of the aspects explored, was Living with exhaustion. Fatigue is the subject of ample work that looks at ways to relieve it and is an aspect investigated predominantly by clinicians.

Another major concern was the inability to control their bowels from Living in a flawed body theme. Continence care for IBD raises a major issue for healthcare professionals. Being afraid of losing bowel control in public and the stigma attached to such an incident was evident from numerous accounts. Body control is a complex process and yet very little is known about it. It is also making us socially acceptable and, although for some who have faecal incontinence may not be seen as an issue, others perceive themselves as not being competent adults (Norton, 2004). Norton et al (2013) suggested that incontinence is still under reported by IBD patients. This may be because insufficient opportunities for the patients to voice such sensitive issues, or others may not be aware there are options to alleviate the severity of incontinence symptoms. In the same study, IBD patients with faecal incontinence reported a lower quality of life and they were also reporting lower social functioning.

The second most common theme alongside Living in a flawed body was Living in secrecy. The difficulty in continuing to live as normal as possible was hindered by the uncertainty of the disease. They lived in a fluid state that was constantly changing and felt powerless in maintaining some sense of control. Not being able to disclose their condition had a negative impact on their psychological and emotional health, resulting in either reducing or withdrawing from social activities. The psychological and emotional baggage attached to the condition remains an un-promoted issue which is still poorly addressed by healthcare professionals (Kemp et al, 2012). The difference between IBD and other invisible chronic illnesses sits in the difficulty of discussing symptoms that can be seen as unacceptable for 
public discussion with others from outside their close circle. This review suggests that patients with IBD perceive themselves as having a 'spoiled identity' (Goffman, 1963) and avoid disclosing their illness, regardless the age of the patients. The secrecy surrounding the condition was an important finding and closely related to perceived stigma and/or fear of not being believed. Stigma surrounding the condition was subject to ample discussions in some of the papers and the need for secrecy adds significantly to the burden of the disease. The lack of public awareness about the condition is a key factor in daily experiences faced by some patients (Bray et al, 2015). Saunders (2014) argues that taboos surrounding the bowel conditions need to be addressed, however this cannot be done by research alone. But what is notable is that all five themes identified have impacts on social relationships and interactions of IBD patients with the 'outside' world become irremediably disrupted. Looking at all the themes, we can conclude that overall, living with IBD means living in some degree of isolation and exclusion.

Evidence from this review is supported by quantitative studies emphasising the extent of the problems by measuring health related quality of life and IBD related concerns (Stjernman et al, 2010; Mussel et al, 2003; Levenstein et al, 2001). A large European survey looking at the international perspective of the impact of IBD on patients' lives gives valuable data from various aspects of life, the burden of symptoms and the delivery of care. It suggests that $96 \%$ of the respondents suffer from fatigue during flares, women aged 19-43 being the most affected. Half of the participants agreed that IBD had negatively affected their work or career pathway and reported their intimate relationships had been affected, rising to $64 \%$ for those with certain types of colitis. The study also revealed that $66 \%$ of the respondents were worried about toilet availability and they considered the presence of a toilet when they planned a trip (Wilson et al, 2012). 
What we found interesting is the fact that a specific age group appeared to get silenced through inclusion in adult research (over 18) in most of the studies. Satisfaction with body image and acceptance by peers are most associated to self-esteem in adolescence (Coleman, 2011), both aspects being of high concern for those living with IBD. This is also important as the illness is diagnosed in over half of the patients between the age of 20 to 29 (Molodecky et al, 2012).

Most of the evaluations on factors influencing the IBD patient quality of life are based on healthcare providers and not patients. Patient accounts of illness experiences are becoming more accepted as an important source of understanding the extent of disruption in the life of those with chronic illness. Looking at patients' perspectives helps define what is of significance to the patient and ultimately helps those involved in their care to improve health related quality of life. This supports providing better care by addressing issues that are important to patients. Social isolation and withdrawal from relationships are major consequences of chronic illness (Straus, 1975) and the evidence from this review suggest that those with IBD could probably be some of the most socially isolated. Evidence into how life changes for IBD patients places the restriction in movement as the most negative outcome (Purc-Stevenson et al, 2014).

\section{Limitations}

This review only included articles in English; thus, language was a barrier to including studies from non-English speaking countries. Considering the lack of diversity within the population in this review, we acknowledge there may be publications that we were unable to access in order to give us a better understanding of the cultural issues posed by the condition. Also, there are differences between the two conditions, CD and UC, regarding the outcomes 
and complications and we have not analysed, separately, experiences particular for each condition.

\section{CONCLUSION}

The qualitative data from this review offers a deeper understanding of the major impact IBD has on their life and their daily struggles, and how their lives changed after diagnosis. We draw on research using patients' own voices to provide a succinct account of their difficulties of daily living. Thus, this information could help improve their quality of life and reduce the burden of their condition.

\section{Recommendations for practice and research}

Healthcare professionals should be aware of the patient perspective and their experience of living with IBD. This should not just cover issues such as symptom burden but also the emotional and psychological aspect if a holistic care approach is the aim. The risk of becoming isolated must be understood and personal circumstances for each individual attending clinical appointments should be familiar to the care providers (see Table 3).

More research is needed to explore the experiences specific to younger adults. Only $3 \%$ of the total sample had specifically looked at 16-24 years olds, which is suggestive of a significant gap in the research undertaken so far. Furthermore, there is a lack of knowledge from wider cultural groups and with a different socio economic status, all those included here having access to good healthcare systems. 
Table 3. Recommendations for practice and research

\begin{tabular}{|l|l|}
\hline Living with exhaustion & $\begin{array}{l}\text { Fatigue should be monitored and underlying } \\
\text { issues such as anaemia or personal } \\
\text { circumstances, to be addressed. Research on } \\
\text { strategies to cope with fatigue should be } \\
\text { done. }\end{array}$ \\
\hline Living in a flawed body & $\begin{array}{l}\text { Referral to specialist continence /pelvic } \\
\text { floor services to provide support in } \\
\text { incontinence management. }\end{array}$ \\
\hline Living with secrecy/ Living with & $\begin{array}{l}\text { Increasing public awareness of the condition } \\
\text { should be prioritised as it would alleviate } \\
\text { the need to conceal the illness. This should } \\
\text { be extended to wider population and include } \\
\text { ethnic minorities where a significant gap in } \\
\text { knowledge was found. }\end{array}$ \\
\hline Living in fear & $\begin{array}{l}\text { Raising awareness of the condition for a } \\
\text { quicker referral to secondary care would } \\
\text { alleviate anxiety. Appropriate level of } \\
\text { information should be provided in terms of } \\
\text { potential complications and long term risks } \\
\text { associated with condition. }\end{array}$ \\
\hline
\end{tabular}

References

Alexakis, C., Nash, A., Lloyd, M.,Brooks, F., Lindsay, J. O., \& Poullis, A. (2015). Inflammatory bowel disease in young patients: challenges faced by black and minority ethnic communities in the UK. Health \& Social Care in the Community, 23, 1-8. https://doi.org/10.1111/hsc. 12188

Aveyard, H., Payne, S., Preston, N. (2016) A postgraduate's guide to doing a literature review in health and social care. $1^{\text {st }}$ Ed. Open University Press.

Barned, C., Stinzi, A., Mack, D., \& O 'doherty, K. C. (2016). To tell or not to tell: A qualitative interview study on disclosure decisions among children with inflammatory bowel disease. Social Science \& Medicine (1982).

https://doi.org/10.1016/j.socscimed.2016.06.023 
Bray, J., Fernandes, A., Nguyen, G. C., Otley, A. R., Heatherington, J., Stretton, J., ... Benchimol, E. I. (2016). The Challenges of Living with Inflammatory Bowel Disease: Summary of a Summit on Patient and Healthcare Provider Perspectives. Canadian Journal of Gastroenterology and Hepatology. https://doi.org/10.1155/2016/9430942

Burger, J. L. (2005). LIVING WITH INFLAMMATORY BOWEL DISEASE: BODILY AND SOCIAL RESPONSES TO ILLNESS. PhD Thesis, Saint Louis University, Missouri. Retrieved from http://search.proquest.com/pqdtglobal/docview/305431217/fulltextPDF/CA516D5B5F7

Casati, J., Toner, B. B., de Rooy, E. C., Drossman, D. A., \& Maunder, R. G. (2000). Concerns of patients with inflammatory bowel disease: a review of emerging themes. Digestive Diseases and Sciences, 45(1), 26-31. Retrieved from http://www.ncbi.nlm.nih.gov/pubmed/10695609

Coleman, J.C., 2011. The nature of adolescence. $4^{\text {th }}$ Ed. Routledge, UK.

Compton, L., (2002). Women Living with Crohn's Disease. Master dissertation, University of Windsor,Detroit. https://doi.org/10.16953/deusbed.74839

Cooper, J. M., Collier, J., James, V., \& Hawkey, C. J. (2010). Beliefs about personal control and self-management in 30-40 year olds living with Inflammatory Bowel Disease: A qualitative study. International Journal of Nursing Studies. https://doi.org/10.1016/j.ijnurstu.2010.05.008

Critical Appraisal Skills Programme (CASP). (2015). Critical Appraisal Skills Programme (CASP). [online] Available at: http://www.casp-uk.net/\#!casp-tools-checklists/c18f8

Czuber-Dochan, W., Dibley, L. B., Terry, H., Ream, E., Norton, C., \& Cqsw, B. (2010). The experience of fatigue in people with inflammatory bowel disease: an exploratory study. Journal of Advanced Nursing, 2(699), 1987-1999. https://doi.org/10.1111/

Daniel, J. M. (2002). Young adults' perceptions of living with chronic inflammatory bowel disease. Gastroenterology Nursing: The Official Journal of the Society of Gastroenterology Nurses and Associates, 25(3), 83-94. Retrieved from http://www.ncbi.nlm.nih.gov/pubmed/12055376

Day, A. S., Ledder, O., Leach, S. T., \& Lemberg, D. a. (2012). Crohn's and colitis in children and adolescents. World Journal of Gastroenterology, 18(41), 5862-5869. https://doi.org/10.3748/wig.v18.i41.586

Defenbaugh, N.L. (2007). Sites of discovery: A narrative journey of the IBD body. PhD Thesis, Southern Illinois University Carbondale.. Retrieved from http://search.proquest.com/pqdtglobal/docview/304826218/fulltextPDF/CA516D5B5F7Delmar,E4759PQ/5?accountid=1304 $\underline{2}$

Devlen, J., Beusterien, K., Yen, L., Ahmed, A., Cheifetz, A. S., \& Moss, A. C. (2014). The Burden of Inflammatory Bowel Disease: A Patient-Reported Qualitative Analysis and Development of a Conceptual Model. Inflammatory Bowel Disease, (20(3): 545-552), https://doi.org/10.1097/01.MIB.0000440983.86659.81

Dibley, L., Norton, C., Schaub, J., Bassett, P., (2014) Experiences of gay and lesbian patients with inflammatory bowel disease: a mixed method study. Gastrointestinal nursing. 12(60, 19-30. DOI10.12698/gasn.2014.12.6.19

Dibley, L. B. (2014). THE EXPERIENCE OF STIGMA IN PEOPLE WITH INFLAMMATORY BOWEL DISEASE, WITH OR WITHOUT INCONTINENCE: A HERMENEUTIC PHENOMENOLOGICAL STUDY. PhD Thesis, Buckinghamshire New University and Coventry University. Retrieved from http://collections.crest.ac.uk/9515/1/THESIS

Dixon-Woods, M., Cavers, D., Agarwal, S., Annandale, E., Arthur, A., Harvey, J., . . Sutton, A. J. (2006). Conducting critical interpretive synthesis of the literature on access to healthcare by vulnerable groups. $B M C$ Medical Research Methodology.

Ellis, C., \& Bochner, A. P. (2000). Autoethnography, personal narrative, reflexivity. In N. K. Denzin \& Y. S. Lincoln (Eds.), Handbook of qualitative research (2nd ed., pp. 733-768). Thousand Oaks, CA: Sage.

Goffman, E. (1963). Stigma: Notes on the management of a spoiled identity. Englewood Cliffs, NJ: Prentice-Hall. 
Hall, N. J., Rubin, G. P., Dougall, A., Hungin, A. P. S., \& Neely, J. (2005). The Fight for "Health- related Normality": A Qualitative Study of the Experiences of Individuals Living with Established Inflammatory Bowel Disease (IBD). Journal of Health Psychology Www.sagepublications.com, 10(3), 443-455. https://doi.org/10.1177/1359105305051433

IBD Standards Group, 2013. Standards for the Healthcare of People who have Inflammatory Bowel Disease (2013 Update), London: IBD Standards Group. Available at: http://www.ibdstandards.org.uk/uploaded files/IBDstandards.pdf.

Kemp, K., Griffiths, J., \& Lovell, K. (2012). Understanding the health and social care needs of people living with IBD: a meta-synthesis of the evidence. World Journal of Gastroenterology : WJG, 18(43), 6240-9.

https://doi.org/10.3748/wjg.v18.i43.6240

Le Roux, C. S. (2016). Exploring rigour in autoethnographic research. International Journal of Social Research Methodology (Online), ISSN homepage, 1364-5579. https://doi.org/10.1080/13645579.2016.1140965

Levenstein, S., Zhiming, L., Almer, S., Barbosa, A., Marquis, P., \& Moser, G., et al. (2001). Cross-cultural variation in disease-related concerns among patients with inflammatory bowel disease. The American Journal of Gastroenterology, 96 (6), 1822- 1830.

Lindfred, H., Saalman, R., Nilsson, S., Sparud-Lundin, C., \& Lepp, M. (2012). Self-reported health, self-management, and the impact of living with inflammatory bowel disease during adolescence. Journal of Pediatric Nursing, 27(3), 256-64. https://doi.org/10.1016/j.pedn.2011.02.005

Lynch, T., \& Spence, D. (2008). A qualitative study of youth living with Crohn disease. Gastroenterology Nursing : The Official Journal of the Society of Gastroenterology Nurses and Associates, 31(3), 224-30-2.

https://doi.org/10.1097/01.SGA.0000324114.01651.65

Matini, L., \& Ogden, J. (2016). A qualitative study of patient's experience of living with inflammatory bowel disease: A preliminary focus on the notion of adaptation. Journal of Health Psychology, 21(11), 2493-2502.

https://doi.org/10.1177/1359105315580463

Medford, K. (2006). Caught with a fake ID: Ethical questions about slippage in autoethnography. Qualitative Inquiry, 12 , 853-864.

Molodecky, N. A., Soon, I. S., Rabi, D. M., Ghali, W. A., Ferris, M., Chernoff, G., ... Kaplan, G. G. (2012). Increasing Incidence and Prevalence of the Inflammatory Bowel Diseases With Time, Based on Systematic Review. YGAST, 142, 4654.e42. https://doi.org/10.1053/j.gastro.2011.10.00

Mowat, C., Cole ,A.,, Windsor ,A., Ahmad, T., Arnott, I., Driscoll, I., Mitton, S.,.Orchard,T., Rutter,M., Younge, L., Lees, C., Ho,G., Satsangi,J., Bloom,S., (2011). Guidelines for the management of inflammatory bowel disease in adults. Gut, 60(5), 571-607. https://doi.org/10.1136/gut.2010.224154

Mukherjee, S., Sloper, P., \& Turnbull, A. (2002). An insight into the experiences of parents with inflammatory bowel disease. Journal of Advanced Nursing, 37(4), 355-63. Retrieved from http://www.ncbi.nlm.nih.gov/pubmed/11872105

Mussell, M., Böcker, U., Nagel, N., \& Singer, M. V. (2004). Predictors of disease-related concerns and other aspects of health-related quality of life in outpatients with inflammatory bowel disease. European Journal of Gastroenterology \& Hepatology, 16(12), 1273-1280. https://doi.org/10.1097/00042737-200412000-00007

Micallef-Konewko, E., (2013) Talking about an Invisible Illness: the Experience of Young People Suffering from Inflammatory Bowel Disease (IBD). Professional doctorate thesis, University of East London.

Nicholas, D. B., Otley, A., Smith, C., Avolio, J., Munk, M., \& Griffiths, A. M. (2007). Challenges and strategies of children and adolescents with inflammatory bowel disease: a qualitative examination. Health and Quality of Life Outcomes, 5, 28. https://doi.org/10.1186/1477-7525-5-28

Norton, C. (2004). Nurses, bowel continence, stigma and taboos. J Wound Ostomy Continence Nurs. 2004 MarApr;31(2):85-94.

Norton, C., \& Dibley, L. (2012). P086 Faecal incontinence in inflammatory bowel disease (IBD) and effect on quality of life. Journal of Crohn's and Colitis, 6(8), S44. https://doi.org/10.1016/S1873-9946(12)60106-8 
Norton, C., \& Dibley, L. (2013). Help-Seeking for Fecal Incontinence in People With Inflammatory Bowel Disease. Journal of Wound, Ostomy and Continence Nursing, 40(6), 631-638. https://doi.org/10.1097/WON.0b013e3182a9a8b5

Palant, A., Koschack, J., Rassmann, S., Lucius-Hoene, G., Karaus, M., \& Himmel, W. (2015). The significance of food for people with inflammatory bowel disease -a qualitative study. BMC Gastroenterology, 15;93. https://doi.org/10.1186/s12876$\underline{015-0322-2}$

Prince, A., Whelan, K., Moosa, A., Lomer, M. C. E., \& Reidlinger, D. P. (2011). Nutritional problems in inflammatory bowel disease: The patient perspective. Journal of Crohn's and Colitis, 5, 443-450.

https://doi.org/10.1016/j.crohns.2011.04.016

Purc-Stephenson, R., Bowlby, D., \& Qaqish, S. T. (2014). “A gift wrapped in barbed wire” Positive and negative life changes after being diagnosed with inflammatory bowel disease. Quality of Life Research, 1197-1205.

https://doi.org/10.1007/s11136-014-0843-0

Richardson, L. (2000). Writing: A method of inquiry. In N. K. Denzin \& Y. S. Lincoln (Eds.), Handbook of qualitative research (2nd ed., pp. 923-948). Thousand Oaks, CA: Sage Publications.

Sammut, J., Scerri, J., \& Borg Xuereb, R. (2015). The lived experience of adults with ulcerative colitis. Journal of Clinical Nursing, (24), 2659-2667. https://doi.org/10.1111/jocn.12892

Saunders, B. (2014). Stigma, deviance and morality in young adults' accounts of inflammatory bowel disease. Sociology of Health \& Illness. https://doi.org/10.1111/1467-9566.12148

Stjernman, H., Tysk, C., Almer, S., Ström, M., \& Hjortswang, H. (2010). Worries and concerns in a large unselected cohort of patients with Crohn's disease. Scandinavian Journal of Gastroenterology, 45(6), 696-706. https://doi.org/10.3109/00365521003734141

Straus, A. (1975). Chronic illness and the quality of life.$^{\text {st }}$ Ed. Mosby

Sykes, D. N., Fletcher, P. C., \& Schneider, M. A. (2015). Balancing my disease: Women's perspectives of living with inflammatory bowel disease. Journal of Clinical Nursing. https://doi.org/10.1111/jocn.12785

Thomas, J., \& Harden, A. (2008). Methods for the thematic synthesis of qualitative research in systematic reviews. BMC Medical Research Methodology, 8(8). https://doi.org/10.1186/1471-2288-8-45

Tong, A., Flemming, K., McInnes, E., Oliver, S., \& Craig, J. (2012). Enhancing transparency in reporting the synthesis of qualitative research: ENTREQ. BMC Medical Research Methodology. https://doi.org/10.1186/1471-2288-12-181

Wilson, B., Lonnfors, S., Hommes, D. W., Vermeire, S., Greco, M., Bell, C., \& Avedano, L. (2012). A European Crohn's and ulcerative colitis patient life IMPACT survey. Journal of Crohn's and Colitis, 6, S171.

https://doi.org/http://dx.doi.org/10.1016/S1873

Whayman K, Duncan J, O'Connor M (2011) Inflammatory Bowel Disease Nursing. Quay Books Division MA Healthcare Ltd, London. 